\title{
Lipase-Catalyzed Synthesis of Aliphatic Polyesters by Polycondensation of Dicarboxylic Acids and Glycols in Solvent-Free System
}

\author{
Hiroshi UYAMA, Kojiro INADA, and Shiro KoBAYASHI ${ }^{\dagger}$ \\ Department of Materials Chemistry, Graduate School of Engineering, Kyoto University, \\ Kyoto 606-8501, Japan
}

(Received December 6, 1999)

\begin{abstract}
Aliphatic polyesters have been synthesized by enzymatic polymerization of dicarboxylic acids and glycols in a solvent-free system. Candida antarctica lipase catalyzed the polymerization under mild reaction conditions, despite the heterogeneous mixture of the monomers and catalyst. Effects of the polymerization conditions were systematically investigated in the polymerization of sebacic acid and 1,4-butanediol. Methylene chain length of the monomers greatly affected the polymer yield and molecular weight. The polymer with molecular weight of more than $1 \times 10^{4}$ was obtained by the reaction under reduced pressure. The addition of a small amount of adjuvant afforded the polymer from the solid monomers.
\end{abstract}

KEY WORDS Enzymatic Polymerization / Lipase / Polyester / Solvent-Free System / Adjuvant /

Lipase-catalyzed polymerizations provide an environmentally friendly methodology of polyester syntheses owing to non-toxic enzyme catalyst and mild reaction conditions. $^{1-7}$ Various monomer combinations have been developed for enzymatic synthesis of polyesters; dicarboxylic acids or their derivatives/glycols, oxyacids, oxyacid esters, lactones, and lactides.

As to enzymatic polycondensations for polyester syntheses, activated esters such as vinyl and 2,2,2trifluoroethyl esters were often used owing to much higher reactivity toward lipase catalyst than acids or alkyl esters. ${ }^{8-14}$ We first reported that lipase efficiently catalyzed the polycondensation of divinyl adipate and 1,4-butanediol, and the polymer formation from adipic acid or diethyl adipate was not observed under the similar reaction conditions. ${ }^{11}$ Afterwards, various vinyl esters were enzymatically polymerized to give aliphatic and aromatic polyesters. ${ }^{12^{-14}}$ Vinyl ester derivatives also acted as an efficient terminator of enzymatic ringopening polymerization of lactone; facile single-step production of polyester macromonomers and telechelics was achieved by lipase-catalyzed polymerization of 13membered lactone in the presence of vinyl esters. ${ }^{15,16}$ However, most of vinyl ester monomers are not commercially available; therefore, they have to be synthesized.

A variety of dicarboxylic acids are commercially available in a relatively cheap price, and hence, their use as monomer for enzymatic polymerization under mild reaction conditions is advantageous for development of an environmentally benign process of aliphatic polyester production in industrial fields. In the lipase-catalyzed polymerization of dicarboxylic acid and glycol in organic solvents, the reaction rate was very slow and the resulting products had low molecular weight. ${ }^{17}$ The increase of the molecular weight more than $1 \times 10^{4}$ was achieved by the pressure reduction of reaction system. ${ }^{18-20}$

Most of dicarboxylic acids are solid, and hence, the enzymatic polymerizations were often performed in organic solvents solubilizing these diacids. Very recently,

\footnotetext{
${ }^{\dagger}$ To whom correspondence should be addressed.
}

Candida antarctica lipase was reported to induce the polymerization of dicarboxylic acids and glycols in a solvent-free system, despite the heterogeneous mixture of the monomers and catalyst. ${ }^{21-23}$ This study deals with our comprehensive results of the enzymatic polymerization of dicarboxylic acids (1) and glycols (2) in bulk (Scheme 1).

\section{RESULTS AND DISCUSSION}

\section{Enzyme Screening}

The polymerization of sebacic acid (1d) with 1,4butanediol (2c) was carried out by using five commercially available lipases of different origin as catalyst in bulk at $60^{\circ} \mathrm{C}$ for 8 or $48 \mathrm{~h}$ (Table I). The catalysts used were lipases derived from Candida antarctica (lipase CA), Mucor miehei (lipase MM), Pseudomonas cepacia (lipase PC), Pseudomonas fluorescens (lipase PF), and porcine pancreas (PPL), which showed high catalytic activity for the lactone polymerizations. ${ }^{24-28}$ Lipases CA and $\mathrm{MM}$ are granular immobilized enzymes and the others are crude powdery ones. Results of the polymerization in diisopropyl ether are also shown. The molecular weight of the polymer was estimated by size exclusion chromatographic (SEC) analysis using tetrahydrofuran (THF) eluent. Polymer structure was confirmed by NMR spectroscopy.

In a solvent-free system, only lipase CA afforded the polyester in a moderate yield (entry 1), which might be due to its high catalytic activity for ester synthesis and/ or the immobilization on the large surface area material. No polymer formation was observed in using other lipases as catalyst, despite longer reaction time $(48 \mathrm{~h})(\mathrm{en}-$ tries $4,6,8$, and 10). These polymerization behaviors were different with those in diisopropyl ether; lipases $\mathrm{MM}$ and $\mathrm{PC}$ as well as lipase CA catalyzed the polymerization in the solvent to give the polyester (entries 3,5 , and 7). In the lipase CA-catalyzed polymerization, the yield of the polymer obtained in bulk was larger than that in diisopropyl ether (entries 1 and 3), indicating that no use of the solvent was more suitable for efficient 


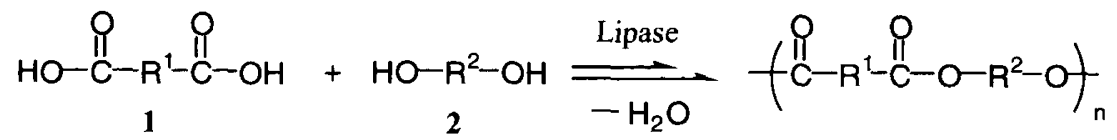

$$
\begin{aligned}
& \text { 1a: } \mathbf{R}^{1}=-\left(\mathrm{CH}_{2}\right)_{2}-\quad \text { 2a: } \mathrm{R}^{2}=-\left(\mathrm{CH}_{2}\right)_{2}- \\
& \text { 1b: } R^{1}=-\left(\mathrm{CH}_{2}\right)_{4}^{-} \quad \text { 2b: } \mathrm{R}^{2}=-\left(\mathrm{CH}_{2}\right)_{3}- \\
& \text { 1c: } \mathrm{R}^{1}=-\left(\mathrm{CH}_{2}\right)_{6}-\quad \text { 2c: } \mathrm{R}^{2}=-\left(\mathrm{CH}_{2}\right)_{4}- \\
& \text { 1d: } \mathrm{R}^{1}=-\left(\mathrm{CH}_{2}\right)_{8}-\quad 2 \mathrm{~d}: \mathrm{R}^{2}=-\left(\mathrm{CH}_{2}\right)_{5}- \\
& \text { le: } R^{1}=-\left(\mathrm{CH}_{2}\right)_{12}-\quad \text { 2e: } R^{2}=-\left(\mathrm{CH}_{2}\right)_{6}^{-} \\
& \text {2f: } \mathrm{R}^{2}=-\left(\mathrm{CH}_{2}\right)_{8}- \\
& \text { 2g: } \mathrm{R}^{2}=-\left(\mathrm{CH}_{2}\right)_{10} \\
& \text { 2h: } \mathrm{R}^{2}=-\left(\mathrm{CH}_{2}\right)_{12}-
\end{aligned}
$$

\begin{tabular}{|c|c|c|c|c|c|c|}
\hline \multirow{2}{*}{ Entry } & \multirow{2}{*}{ Catalyst } & \multirow{2}{*}{ Solvent } & \multirow{2}{*}{$\frac{\text { Time }}{\mathrm{h}}$} & \multirow{2}{*}{$\frac{\text { Yield }^{\mathrm{b}}}{\%}$} & \multirow{2}{*}{\multicolumn{2}{|c|}{$M_{n}{ }^{\mathrm{c}} M_{w} / M_{n}$}} \\
\hline & & & & & & \\
\hline 1 & Lipase CA & Bulk & 8 & 56 & 3800 & 1.3 \\
\hline 2 & Lipase $\mathrm{CA}^{\mathrm{d}}$ & Bulk & 8 & 0 & & \\
\hline 3 & Lipase CA & Diisopropyl Ether & 8 & 34 & 2000 & 1.3 \\
\hline 4 & Lipase MM & Bulk & 48 & 0 & & \\
\hline 5 & Lipase MM & Diisopropyl Ether & 48 & 54 & 2700 & 1.4 \\
\hline 6 & Lipase PC & Bulk & 48 & 0 & & \\
\hline 7 & Lipase PC & Diisopropyl Ether & 48 & 5 & 1500 & 1.1 \\
\hline 8 & Lipase PF & Bulk & 48 & 0 & & \\
\hline 9 & Lipase PF & Diisopropyl Ether & 48 & 0 & & \\
\hline 10 & PPL & Bulk & 48 & 0 & & \\
\hline 11 & PPL & Diisopropyl Ether & 48 & 0 & & \\
\hline 12 & - e $^{\mathrm{e}}$ & Bulk & 48 & 0 & & \\
\hline
\end{tabular}

Scheme 1.

Table I. Enzyme Screen for Polycondensation of $1 d$ and $2 c^{a}$

${ }^{a}$ Polymerization of $1 \mathrm{~d}$ and $2 \mathrm{c}$ (each $2.0 \mathrm{mmol}$ ) using lipase catalyst $(100 \mathrm{mg})$ at $60^{\circ} \mathrm{C}$. ${ }^{\mathrm{b}}$ Methanol-insoluble part. ${ }^{\mathrm{c}}$ Determined by SEC. ${ }^{\mathrm{d}}$ Deactivated enzyme. ${ }^{\mathrm{e}}$ Control experiment.

enzymatic production of polyesters. In the polymerization without enzyme (control experiment), the monomers were recovered unchanged (entry 12). Furthermore, no polymer formation was observed in using the deactivated lipase $\mathrm{CA}^{28}$ (entry 2). These data imply that the present polymerization proceeded through lipase catalysis.

\section{Effects of Reaction Conditions}

Effects of reaction time and temperature have been investigated (Table II). The yield of the polymer obtained for $2 \mathrm{~h}$ was lower than that for $4 \mathrm{~h}$ (entries 1 and 2 ). After $4 \mathrm{~h}$, the polymer yield was almost constant (56-63 $\%$, entries 2, 4, and 6). Our previous study ${ }^{29}$ on the lipase-catalyzed polymerization of divinyl sebacate and 1,4-butanediol showed that the oligomeric products were soluble in methanol; therefore, they were lost during the isolation procedures, resulting in the moderate yield of the polymer. The molecular weight also scarcely changed during the polymerization.

The polymerization at $50^{\circ} \mathrm{C}$ produced the polymer

\begin{tabular}{|c|c|c|c|c|c|}
\hline \multirow{2}{*}{ Entry } & Time & Temperature & Yield $^{b}$ & \multirow{2}{*}{$M_{n}{ }^{\mathrm{c}}$} & \multirow{2}{*}{$M_{w} / M_{n}$} \\
\hline & $\mathrm{h}$ & ${ }^{\circ} \mathrm{C}$ & $\%$ & & \\
\hline 1 & 2 & 60 & 21 & 2700 & 1.2 \\
\hline 2 & 4 & 60 & 59 & 3000 & 1.3 \\
\hline 3 & 8 & 50 & 28 & 2300 & 1.2 \\
\hline 4 & 8 & 60 & 56 & 3800 & 1.3 \\
\hline 5 & 8 & 70 & 55 & 3300 & 1.5 \\
\hline 6 & 24 & 60 & 63 & 3400 & 1.3 \\
\hline
\end{tabular}
with lower molecular weight in a lower yield than that at 60 or $70^{\circ} \mathrm{C}$ (entries $3-5$ ), which might be because the substrates and resulting polymer are more mobile in bulk at higher temperature. These behaviors were different with those of lipase PC-catalyzed polymerization
Table II. Effects of Polymerization Conditions between $1 \mathrm{~d}$ and $2 \mathrm{c}^{\mathrm{a}}$

${ }^{a}$ Polymerization of $1 \mathbf{d}$ and $2 \mathbf{c}$ (each $2.0 \mathrm{mmol}$ ) using lipase CA catalyst $(100 \mathrm{mg})$ in bulk. ${ }^{\mathrm{b}}$ Methanol-insoluble part. ${ }^{\mathrm{c}}$ Determined by SEC.

of divinyl sebacate with 1,4-butanediol in diisopropyl ether; the yield and molecular weight of the polymer obtained at $45^{\circ} \mathrm{C}$ were larger than those at $60^{\circ} \mathrm{C} .{ }^{29}$

\section{Effects of Monomer Structure}

In the lipase-catalyzed polymerizations of $\alpha, \omega$ alkylene diacids and glycols, the methylene chain length strongly affected the polymerization behaviors. In case of the dehydration polycondensation of dicarboxylic acid and glycol catalyzed by lipase PC in water, the polymerization behaviors strongly depended on the hydrophobicity of the monomers. ${ }^{30}$ When the dicarboxylic acid monomer was fixed as sebacic acid (1d), the polymer yield increased as a function of methylene length from 2 to 10 in glycols (2a-2g) (entries 7-13) and the polymer formation was not observed in using 1,12-dodecanediol (2h) (entry 14). At the polymerization temperature $\left(60^{\circ} \mathrm{C}\right)$, glycols $(\mathbf{2 a}-\mathbf{2 f})$ were liquid and $\mathbf{2} \mathbf{g}$ was partly liquid (melting point of $2 \mathrm{~g}=73^{\circ} \mathrm{C}$ ), whereas the melting point of $2 \mathbf{h}\left(82^{\circ} \mathrm{C}\right)$ was much higher than the reaction temperature. Thus, the polymerization of $1 \mathbf{d}$ with $\mathbf{2 h}$ was carried out at $70^{\circ} \mathrm{C}$ to give the polymer in a high yield (entry 15). The molecular weight did not change so much except that from ethylene glycol (2a).

The effect of the methylene chain length of 1 was examined with fixing the glycol monomer as 2c. The polymerization of a diacid with short methylene length (1a or 1b) produced the polymer in a very low yield (entries 2 and 4). In using sebacic acid (1d), the polymer yield 
Table III. Effects of Monomer Structure ${ }^{a}$

\begin{tabular}{|c|c|c|c|c|c|}
\hline \multirow{2}{*}{ Entry } & \multicolumn{2}{|c|}{ Monomers } & \multirow{2}{*}{$\frac{\text { Yield }^{\mathrm{b}}}{\%}$} & \multirow{2}{*}{$M_{n}^{\mathrm{c}}$} & \multirow{2}{*}{$M_{w} / M_{n}{ }^{\mathrm{c}}$} \\
\hline & 1 & 2 & & & \\
\hline 1 & $1 \mathbf{a}$ & $\mathbf{2 a}$ & 0 & & \\
\hline 2 & $1 a$ & $\mathbf{2 c}$ & 3 & 1700 & 1.5 \\
\hline 3 & $1 b$ & $\mathbf{2 a}$ & 4 & 1300 & 1.5 \\
\hline 4 & $1 b$ & $2 c$ & 8 & 2900 & 1.2 \\
\hline 5 & $1 b$ & $2 f$ & 69 & 4000 & 1.5 \\
\hline 6 & $1 \mathrm{c}$ & $2 c$ & 18 & 3400 & 1.4 \\
\hline 7 & 1d & $2 a$ & 20 & 1700 & 1.2 \\
\hline 8 & 1d & $\mathbf{2 b}$ & 36 & 3900 & 1.4 \\
\hline 9 & $1 d$ & $2 c$ & 56 & 3800 & 1.3 \\
\hline 10 & $1 d$ & $2 d$ & 57 & 4100 & 1.3 \\
\hline 11 & 1d & $\mathbf{2 e}$ & 68 & 4300 & 1.4 \\
\hline 12 & $1 \mathrm{~d}$ & $2 f$ & 73 & 3800 & 1.5 \\
\hline 13 & 1d & $2 \mathrm{~g}$ & 77 & 3300 & 1.5 \\
\hline 14 & $1 d$ & $\mathbf{2 h}$ & 0 & & \\
\hline $15^{\mathrm{d}}$ & $1 d$ & $2 \mathbf{h}$ & 87 & 4900 & 1.7 \\
\hline 16 & $1 e$ & $2 \mathbf{a}$ & 6 & 1300 & 1.1 \\
\hline 17 & $1 \mathrm{e}$ & 2c & 42 & 1900 & 1.3 \\
\hline 18 & $1 e$ & $2 \mathrm{f}$ & 31 & 2200 & 1.4 \\
\hline
\end{tabular}

${ }^{a}$ Polymerization of 1 and 2 (each $2.0 \mathrm{mmol}$ ) using lipase CA catalyst $(100 \mathrm{mg})$ in bulk at $60^{\circ} \mathrm{C}$ for $8 \mathrm{~h} .{ }^{b}$ Methanol-insoluble part. ${ }^{\mathrm{c}}$ Determined by SEC. ${ }^{\mathrm{d}}$ Polymerization temperature at $70^{\circ} \mathrm{C}$.

and molecular weight were the highest (entry 9). These results might be related to the recognition of lipase $\mathrm{CA}$ toward the diacid monomers and/or properties of the resulting polymer. Besides $\alpha, \omega$-alkylene diacids, maleic and fumaric acids were employed, however, no polymer formation was observed.

In case of the polymerization of $\mathbf{2 a}$ with dicarboxylic acids of different methylene chain length, the polymer was not obtained from succinic acid (1 a) (entry 1) and the polymer yield was low in using $\mathbf{1 b}, \mathbf{1 d}$, or 1e (entry 2,7 , and 16 ). The low yield from $\mathbf{2 a}$ was also observed in the enzymatic polymerization with divinyl esters in organic solvents. When 1,8-octanediol (2f) was used as glycol monomer, adipic and sebacic acids produced the polymers in good yields (entries 5 and 12), whereas the yield and molecular weight from 1,14-tetradecanedioic acid were not high (entry 18 ).

As a glycol monomer containing secondary alcohol group, 1,2-propanediol, 1,3-butanediol, and 2,4pentanediol were tested. Only 1,3-butanediol was polymerized with sebacic acid to give the polymer with molecular weight of 6400 in $9 \%$ yield. The polymer was not obtained from other monomers.

\section{Polymerization under Reduced Pressure}

In order to increase the molecular weight in the enzymatic synthesis of polyesters, the polymerization was carried out under reduced pressure. The leaving group (water or alcohol) was removed from the reaction mixture, leading to the shift of the equilibrium to the polymer.

In this study, the polymerization of $\mathbf{1} \mathbf{d}$ and glycols was performed at 90 torr (Table IV). The significant increase of the molecular weight was seen from $2 \mathbf{d}$ (entry 2). The reduction of the pressure improved the yield in using $\mathbf{2 c}$, 2d, and 2f. On the other hand, the yield and molecular weight of the polymer obtained from $2 \mathbf{g}$ under the reduced pressure were almost the same as those under ambient pressure (entry 4), and the highly reduced pressure (1.5 torr) scarcely affected the polymerization be-
Table IV. Enzymatic Polycondensation under Reduced Pressure $^{\text {a }}$

\begin{tabular}{|c|c|c|c|c|c|}
\hline \multirow{2}{*}{ Entry } & \multirow{2}{*}{ Glycol } & Pressure & Yield $^{\mathrm{b}}$ & \multirow{2}{*}{$M_{n}{ }^{\mathrm{c}}$} & \multirow{2}{*}{$M_{w} / M_{n}{ }^{\mathrm{c}}$} \\
\hline & & torr & $\%$ & & \\
\hline 1 & $2 c$ & 90 & 80 & 6700 & 1.6 \\
\hline 2 & 2d & 90 & 86 & 14000 & 2.3 \\
\hline 3 & $2 f$ & 90 & 83 & 3800 & 1.4 \\
\hline 4 & $2 \mathrm{~g}$ & 90 & 48 & 2300 & 1.3 \\
\hline 5 & $2 g$ & 1.5 & 38 & 2300 & 1.3 \\
\hline
\end{tabular}

${ }^{a}$ Polymerization of $\mathbf{1 d}$ and $\mathbf{2}$ (each $2.0 \mathrm{mmol}$ ) using lipase CA catalyst $\left(100 \mathrm{mg}\right.$ ) in bulk for $48 \mathrm{~h} .{ }^{b}$ Methanol-insoluble part. ${ }^{\mathrm{c}}$ Determined by SEC.

Table V. Enzymatic Polymerization of $\mathbf{1 d}$ and $\mathbf{2 h}$ in the Presence of Adjuvant ${ }^{a}$

\begin{tabular}{|c|c|c|c|c|}
\hline \multirow{2}{*}{ Entr } & \multirow{2}{*}{ Adjuvant $^{\mathrm{b}}$} & \multirow{2}{*}{$\frac{\text { Yield }^{c}}{\%}$} & \multirow{2}{*}{$M_{n}^{\mathrm{d}}$} & \multirow{2}{*}{$M_{w} / M_{n}^{\mathrm{d}}$} \\
\hline & & & & \\
\hline $1 \gamma$ & -Butyrolactone (0.010) & 2 & 3200 & 1.7 \\
\hline $2 \gamma$ & -Butyrolactone $(0.050)$ & 10 & 3200 & 1.5 \\
\hline $3 \gamma$ & $v$-Butyrolactone $(0.20)$ & 68 & 2700 & 1.3 \\
\hline $4 \mathrm{D}$ & Diethylene glycol dimethyl ether $(0.010)$ & 1 & 2900 & 1.6 \\
\hline $5 \mathrm{D}$ & Diethylene glycol dimethyl ether $(0.050)$ & 12 & 2900 & 1.4 \\
\hline $6 \mathrm{D}$ & Diethylene glycol dimethyl ether $(0.20)$ & 64 & 2300 & 1.3 \\
\hline $7 m$ & $n$-Dimethoxybenzene $(0.20)$ & 41 & 2800 & 1.5 \\
\hline $8 \mathrm{D}$ & Diphenyl ether $(0.20)$ & 21 & 3900 & 1.9 \\
\hline $9 P$ & Propylene carbonate $(0.20)$ & 35 & 2600 & 1.3 \\
\hline $10 m$ & $n$-Xylene $(0.20)$ & 21 & 3600 & 1.9 \\
\hline
\end{tabular}

${ }^{a}$ Polymerization of $\mathbf{1 d}$ and $\mathbf{2 h}$ (each $2.0 \mathrm{mmol}$ ) using lipase CA catalyst $(100 \mathrm{mg})$ in the presence of adjuvant in bulk at $60^{\circ} \mathrm{C}$ for $8 \mathrm{~h}$. ${ }^{\mathrm{b}}$ In parenthesis, adjuvant volume (mL). ${ }^{\mathrm{c}}$ Methanolinsoluble part. ${ }^{d}$ Determined by SEC.

havior (entry 5 ).

\section{Effect of Adjuvant}

In enzymatic coupling of peptides without solvents, a small amount of adjuvant (inert organic liquid) was often added to the reaction mixture to improve the reaction rate and product yield. ${ }^{31,32}$ As described above, no polymer formation was observed when both monomers were solid at the reaction temperature (entry 14 in Table III). Here, the polymerization of solid sebacic acid (1d) and 1,12-dodecanediol ( $2 \mathbf{h})$ was performed in the presence of a small amount of adjuvant (Table V).

The adjuvant of $0.2 \mathrm{~mL}$ was used for $0.81 \mathrm{~g}$ of the total monomers. All the adjuvants examined in this study were effective for the polymerization of the solid monomers. Relatively high yields were achieved in using $\gamma$ butyrolactone and diethylene glycol dimethyl ether (entries 3 and 6). Four- and more than 6-membered lactones and 6-membered cyclic carbonate were susceptible to enzymatic ring-opening polymerizations, yielding the corresponding polyesters and polycarbonate. ${ }^{24-28,33}$ On the other hand, 5-membered lactone ( $\gamma$-butyrolactone) and cyclic carbonate (propylene carbonate) acted as an efficient adjuvant for the present polymerization (entries 3 and 9). ${ }^{1} \mathrm{H}$ NMR spectrum of the polymer obtained in the presence of these compounds was quite the same as that without the adjuvant, ${ }^{29}$ indicating that the adjuvant was not incorporated into the resulting polymer. The polymer yield increased as a function of the adjuvant amount in the range from $0.01 \mathrm{~mL}$ to $0.2 \mathrm{~mL}$ (entries $1-6)$. 


\section{CONCLUSION}

Candida antarctica lipase efficiently catalyzed the polycondensation of $\alpha, \omega$-alkylene dicarboxylic acids and glycols in a solvent-free system. The methylene length of the monomers strongly affected the polymerization behaviors. The polymer molecular weight increased under the reduced pressure. The polymer formation was observed even from the combination of solid monomers by the addition of a small amount of adjuvant. The present reaction system affords a variety of biodegradable aliphatic polyesters via non-toxic enzyme catalysis under mild reaction conditions without (or with a little amount of ) organic solvents. Therefore, it is environmentally benign and provides an example of "Green Polymer Chemistry".

\section{EXPERIMENTAL}

\section{Materials}

Lipases CA and MM were gifts from Novo Nordisk Bioindustry, Ltd. PPL was purchased from Sigma Chemical Co. Lipases PC and PF were donated by Amano Pharmaceutical Co. Diisopropyl ether and liquid monomers were stored over freshly activated type 4 molecular sieves. Lipase catalysts and other reagents were used as received.

\section{Lipase-Catalyzed Polymerization of Dicarboxylic Acid and Glycol in Bulk}

A typical run was as follows (entry 1 in Table I). A mixture of $0.41 \mathrm{~g}(2.0 \mathrm{mmol})$ of sebacic acid, $0.18 \mathrm{~g}(2.0$ $\mathrm{mmol}$ ) of 1,4-butanediol, and $0.10 \mathrm{~g}$ of lipase CA were placed in a dried tube under argon and sealed. The tube was kept under gentle stirring at $60^{\circ} \mathrm{C}$ for $8 \mathrm{~h}$. A small amount of chloroform was added to the mixture and the part of the organic solution was separated by filtration. The filtrate was poured into a large amount of methanol. The resulting precipitates were collected by centrifugation, followed by drying in vacuo to give $0.29 \mathrm{~g}$ of the polymer (yield 56\%).

\section{Measurements}

SEC analysis was carried out using a Tosoh SC8010 apparatus with a refractive index (RI) detector under the following conditions: TSKgel $\mathrm{G}^{3000 \mathrm{H}_{\mathrm{HR}} \text { column }}$

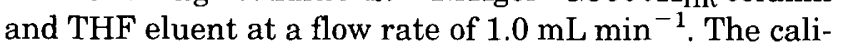
bration curves for SEC analysis were obtained using polystyrene standards. NMR spectra were recorded on a Bruker DPX400 spectrometer.

Acknowledgments. This work was supported by a Grant-in-Aid for Specially Promoted Research (No. 08102002) from the Ministry of Education, Science, Sports and Culture, Japan. We appreciate the gifts of lipases from Novo Nordisk Bioindustry, Ltd. and Amano Pharmaceutical Co.

\section{REFERENCES AND NOTES}

1. S. Kobayashi, J. Polym. Sci., Polym. Chem. Ed., 37, 3041 (1999).

2. S. Kobayashi, S. Shoda, and H. Uyama, "The Polymeric Materials Encyclopedia”, J. C. Salamone, Ed., CRC Press, Boca Raton, 1996, pp 2102-2107.

3. S. Kobayashi, S. Shoda, and H. Uyama, "Catalysis in Precision Polymerization", S. Kobayashi, Ed., John Wiley \& Sons, Chichester, Chapter 8, 1997.

4. H. Ritter, Trends Polym. Sci., 1, 171 (1993).

5. S. Kobayashi and H. Uyama, "Materials Science and Technology-Synthesis of Polymers," A.-D. Schlüter, Ed., Wiley-VCH, Weinheim, Chap. 16, 1998.

6. R. A. Gross, D. L. Kaplan, and G. Swift, Ed., ACS Symp. Ser., 684 (1998).

7. S. Kobayashi, J. Polym. Sci., Polym. Chem. Ed., 37, 3041 (1999).

8. J. S. Wallace and C. J. Morros, J. Polym. Sci., Polym. Chem. Ed., 27, 2553 (1989).

9. V. D. Athawale and S. R. Gaonkar, Biotechnol. Lett., 16, 149 (1994).

10. A. W. P. Jarvie, B. K. Samra, and A. J. Wiggett, J. Chem. Res. (S), 129 (1996).

11. H. Uyama and S. Kobayashi, Chem. Lett., 1687 (1994).

12. A. K. Chaudhary, E. J. Beckman, and A. J. Russell, J. Am. Chem. Soc., 117, 3728 (1995).

13. H. Uyama, S. Yaguchi, and S. Kobayashi, Polym. J., 31, 380 (1999).

14. H. Uyama, K. Inada, and S. Kobayashi, Macromol. Rapid Commun., 20, 171 (1999)

15. H. Uyama, H. Kikuchi, and S. Kobayashi, Chem. Lett., 1047 (1995).

16. H. Uyama, H. Kikuchi, and S. Kobayashi, Bull. Chem. Soc. Jpn., 70, 1691 (1997).

17. F. Binns, S. M. Roberts, A. Taylor, and C. F. Williams, J. Chem. Soc., Perkin Trans. 1, 899 (1993).

18. E. M. Brazwell, D. Y. Filos, and C. J. Morrow, J. Polym. Sci. Polym. Chem. Ed., 33, 89 (1995).

19. Y.-Y. Linko, Z.-L. Wang, and J. Seppalä, J. Biotechnol., 40, 133 (1995).

20. Z.-L. Wang, K. Hiltunen, P. Orava, J. Seppalä, and Y.-Y. Linko, J. Macromol. Sci.-Pure Appl. Chem., A33, 599 (1996).

21. F. Binns, P. Harffey, S. M. Roberts, and A. Taylor, J. Polym. Sci., Polym. Chem. Ed., 36, 2069 (1998)

22. H. Uyama, K. Inada, and S. Kobayashi, Chem. Lett., 1285 (1998).

23. F. Binns, P. Harffey, S. M. Roberts, and A. Taylor, J. Chem. Soc., Perkin Trans. 1, 2671 (1999).

24. H. Uyama, K. Takeya, and S. Kobayashi, Bull. Chem. Soc. Jpn., 68, 56 (1995).

25. H. Uyama, K. Takeya, N. Hoshi, and S. Kobayashi, Macromolecules, 28, 7046 (1995)

26. H. Uyama, H, Kikuchi, K. Takeya, and S. Kobayashi, Acta Polymerica, 47, 357 (1996).

27. S. Namekawa, H. Uyama, and S. Kobayashi, Proc. Jpn. Acad., 74B, 65 (1998).

28. S. Kobayashi, K. Takeya, S. Suda, and H. Uyama, Macromol. Chem. Phys., 199, 1729 (1998).

29. H. Uyama, S. Yaguchi, and S. Kobayashi, J. Polym. Sci., Polym. Chem. Ed., 37, 2737 (1999).

30. S. Suda, H. Uyama, and S. Kobayashi, Proc Acad. Jpn., 75B, 201 (1999).

31. I. Gill and E. N. Vulfson, J. Am. Chem. Soc., 115, 3348 (1993).

32. R. López-Frandino, I. Gill, and E. N. Vulfson, Biotechnol. Bioeng., 43, 1024 (1994).

33. S. Kobayashi, H. Kikuchi, and H. Uyama, Macromol. Rapid Commun., 18, 575 (1997). 